\title{
Volition and Action in the Human Brain: Processes, Pathologies, and Reasons
}

\author{
Itzhak Fried, ${ }^{1,2}$ Patrick Haggard, ${ }^{3,4}$ Biyu J. He, ${ }^{5}$ and ${ }^{-A a r o n ~ S c h u r g e r ~}{ }^{6,7}$ \\ ${ }^{1}$ Department of Neurosurgery and Semel Institute for Neuroscience and Human Behavior, University of California-Los Angeles, Los Angeles, California \\ 90024, ${ }^{2}$ Functional Neurosurgery Unit, Tel Aviv Sourasky Medical Center and Sackler Faculty of Medicine, Tel Aviv University, Tel Aviv 64239, Israel, \\ ${ }^{3}$ Institute of Cognitive Neuroscience, University College London, London WC1N 3AR, United Kingdom, ${ }^{4}$ Institute of Philosophy, School of Advanced Study, \\ University of London, London WC1E 7HU, United Kingdom, ${ }^{5}$ Departments of Neurology, Neuroscience and Physiology, and Radiology, New York

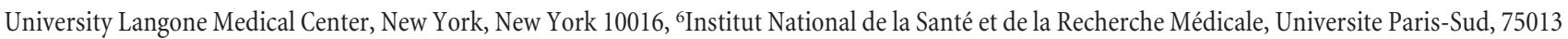 \\ Paris, France, and ${ }^{7}$ Cognitive Neuroimaging Unit, NeuroSpin, CEA-Saclay, 91191 Gif-sur-Yvette cedex, France
}

Humans seem to decide for themselves what to do, and when to do it. This distinctive capacity may emerge from an ability, shared with other animals, to make decisions for action that are related to future goals, or at least free from the constraints of immediate environmental inputs. Studying such volitional acts proves a major challenge for neuroscience. This review highlights key mechanisms in the generation of voluntary, as opposed to stimulus-driven actions, and highlights three issues. The first part focuses on the apparent spontaneity of voluntary action. The second part focuses on one of the most distinctive, but elusive, features of volition, namely, its link to conscious experience, and reviews stimulation and patient studies of the cortical basis of conscious volition down to the single-neuron level. Finally, we consider the goal-directedness of voluntary action, and discuss how internal generation of action can be linked to goals and reasons.

Key words: action; awareness; human; neuropsychology; stochastic; volition

\section{Introduction}

How to define voluntary action? Neuroanatomical descriptions since Sherrington (1906) refer to a voluntary motor pathway, centered on the "final common path" through the primary motor cortex. Neurophysiological accounts refer to internal generation, as opposed to external triggering, of motor action (Passingham, 1987; Passingham et al., 2010). Moreover, internal generation of action was localized to MFC, which may bridge between the subcortical structures for motivation and motor drive, and the primary motor cortex. These accounts did not define the cause of internally generated actions, so are effectively definitions by exclusion. Some computational accounts have also invoked definitions by exclusion, as when referring to "freedom from immediacy" in decision-making (Gold and Shadlen, 2003). Thus, no general, satisfactory, positive definition of voluntary action exists.

Nevertheless, compelling evidence from direct brain stimulation demonstrates a distinctive neural mechanism of volition.

Received Sept. 8, 2017; revised Sept. 30, 2017; accepted 0ct. 3, 2017.

This work was supported by European Research Council Advanced Grant HUMVOL 323943 to P.H., the Bertarelli Foundation, and the Intramural Research Program of the National Institutes of Health/National Institute of Neurological Disorders and Stroke to B.J.H. A.S. was supported in part by European Research Council Starting Grant 640626. B.J.H. was supported by the Leon Levy Foundation and Klingenstein-Simons Fellowship. We thank Dan Sugrue, Brian Maniscalco, and Elisa Brann for advice and assistance.

The authors declare no competing financial interests.

I.F., P.H., B.J.H., and A.S. contributed equally to this work and are listed in alphabetical order.

Correspondence should be addressed to Dr. Patrick Haggard, Institute of Cognitive Neuroscience, University College London, Alexandra House, 17 Queen Square, London WC1N 3AR, United Kingdom. E-mail: p.haggard@ucl.ac.uk.

DOI:10.1523/JNEUROSCI.2584-17.2017

Copyright $(2017$ the authors $\quad 0270-6474 / 17 / 3710842-06 \$ 15.00 / 0$
Stimulation of distinct cortical areas in neurosurgical patients sometimes produces sensations described as "urge to move" a specific body part (Fried et al., 1991; Desmurget et al., 2009). This sensation occurs without any movement of the corresponding effector, but when higher current levels are applied at an "urge site," the corresponding effector will often move (Fried et al., 1991; Haggard, 2011). These effects are associated with stimulation of the supplementary and presupplementary motor areas. When such stimulations additionally evoke an overt movement, the patients experience "ownership" with respect to the movement. This contrasts with stimulations of the primary motor area, where patients clearly "disown" the movement and perceive it as externally imposed. Although it remains unclear precisely which cortical regions are preferentially associated with this "artificial volition," the phenomenon itself seems robust. Based on such findings, we suggest a cluster of several distinctive features of volitional actions, which help to distinguish them from other classes of movement (Table 1). Interestingly, most of these features of voluntary movement can be linked to a specific neuroanatomical or neurophysiological substrate.

Neurophysiological studies to date have generally focused on just one feature of voluntary actions, namely, their internally generated quality. In this paper, we review recent research focusing on three other key features. The first section deals with the question of spontaneity and predictability, and discusses how a stochastic neural process may account for the timing of voluntary actions. The second section deals with the link to conscious experience, and the third section deals with goal-directedness. 
Table 1. Key features of volitional control ${ }^{a}$

\begin{tabular}{ll}
\hline $\begin{array}{l}\text { Key feature of volitional } \\
\text { control }\end{array}$ & $\begin{array}{l}\text { Constraint on neuroanatomical bases of volitional } \\
\text { control }\end{array}$ \\
\hline Leads to movement & $\begin{array}{l}\text { Strong connections to motor areas } \\
\text { Reasons-responsive }\end{array}$ \\
Outcome/goal-directed & $\begin{array}{l}\text { Strong connections from valence/reward circuits } \\
\text { No external trigger }\end{array}$ \\
Innovative/spontaneous & Weak connections from sensory areas \\
Involves consciousness & Independence from subcortical "habitual" circuits \\
\hline
\end{tabular}

${ }^{a}$ No single feature is strictly necessary for an action to be volitional, but a subset of features may be jointly sufficient. Each feature imposes a constraint on brain circuitry for volitional control.

\section{The neural process of internal generation}

Most people feel they know when their acts are voluntary, and when they are not. This first-person certainty betrays the fact that the notion of voluntary action is tightly intertwined with the phenomenon of consciousness: most perspectives on voluntary action appeal to some notion of conscious control, and it is difficult to approach the concept of voluntary action without some mention of consciousness. A recent theory of consciousness holds that consciousness is a perceptual attribution (Graziano and Kastner, 2011): we attribute consciousness in general, and conscious perceptual states in particular, to beings, including ourselves, precisely when we perceive those beings or those states as being conscious. Thus, echoing a prior philosophical idea (Dennett and Kinsbourne, 1992), this theory holds that there is no fact of the matter about consciousness per se. The only relevant fact is whether or not we perceive an agent or a state as being conscious.

One might argue that the same also holds true for voluntary action: what makes an action (our own or that of another) "voluntary" is simply that we perceive it to be so. The first-person is the principal and ultimate arbiter of volition. According to this view, "voluntary action" is a perceptual category in much the same way that "face" or "tree" is a perceptual category: it may or may not refer to a well-defined category in nature. Interestingly, "involuntary" may be a better-defined perceptual category than "voluntary." Thus, a useful scientific approach to volition involves comparing actions that one would perceive to be involuntary and then pointing to what is left over in voluntary actions, a definition by exclusion (Wittgenstein, 1967). This project would likely lead to excluding highly automatized behaviors, simple reflexes (including swatting a mosquito), tics, and tremors. One might also be tempted to exclude otherwise voluntary actions performed under duress, although one would not necessarily consider actions performed under duress to be "involuntary." Such actions may be a special case of volitional control being influenced by an external imperative, and so these would remain in the "voluntary" category. The question of whether such actions should be treated as voluntary or not has been viewed as directly relevant to their legal status (Caspar et al., 2016). Certain responses to sensory cues may still be perceived as voluntary according to this definition (e.g., willingly performing an action after being instructed to do so). Nevertheless, the canonical form of voluntary action is self-initiated action (SIA), which we define as voluntary action initiated without any sensory cue.

One early paradigm for studying SIAs required participants to perform a specific movement (e.g., extension of the index finger) repeatedly at irregular intervals of at least 15 or $20 \mathrm{~s}$. Using this paradigm, Kornhuber and Deecke (2016) discovered the cortical Bereitschaftspotential or "readiness potential" (RP), a slow buildup of scalp electrical potential preceding SIAs. Although this paradigm is effective in revealing this particular neural signal, it lacks ecological validity. For example, choice regarding whether and how to act is lacking, so it might be seen as a self-paced movement task rather than a true SIA task. However, other, perhaps richer tasks can also elicit a RP in the movement-locked average. Recently, a variant of a classical "patch-leaving" task has been used to study SIAs (Khalighinejad et al., 2017) and has been shown to elicit a clear RP.

The RP has long been presumed to reflect a process of "planning and preparation for movement" and is often considered to be a hallmark of voluntary action, but this interpretation has recently been challenged. Schurger et al. (2012) have proposed that the continual background ebb and flow of brain activity influences when voluntary actions will occur. These fluctuations continually bring the motor system closer to or farther from a threshold for movement initiation, so that movement onset is more likely when these fluctuations happen to near the threshold. Thus, the RP might simply reflect random fluctuations of the autocorrelated EEG signal, caught in the "flash photo" of movementlocked averaging. This account has been used to explain the characteristic appearance of the mean RP (Schurger et al., 2012; Khalighinejad et al., 2017).

More recently Fried et al. (2011) found that voluntary action is preceded by progressive recruitment of medial frontal neurons in the SMA, pre-SMA, and anterior cingulate cortex. As the point of reported conscious volition (W) is approached, more neurons join in, and these neurons gradually increase or decrease their firing rate. Prediction of the presence and timing of $\mathrm{W}$ is more accurate as W is approached, and can be modeled as an "Integrate and Fire" model (Fried et al., 2011). In this model, volition emerges once a change in internally generated firing rates of neuronal assemblies crosses a threshold.

The alternative interpretation of the RP, and associated neuronal buildup and recruitment, challenges its status as a marker of volition. The challenge revives the classic question of when, in the time course leading up to an SIA, is the final neuronal commitment to trigger the action. A simple theory might link RP onset to the decision to act (Libet et al., 1983), but RP onset was variable across different studies, and moreover varied widely with the measurement technique used. This may be because the early tail of the RP primarily reflects random autocorrelated fluctuations in neural activity, and thus has no "onset" event per se. Rather, it extends arbitrarily far back in time, decaying exponentially or according to a power law. The temporal relationship between the RP and the estimated time of the subjective decision to act was previously used to argue that the conscious decision to act cannot possibly be responsible for the action because the onset of the RP precedes the estimated time of the subjective decision by hundreds of milliseconds (Libet et al., 1983). The new challenge from fluctuation models renders this argument suspect.

If voluntary action is reliably linked to a specific process in the brain, then in principle "voluntary action" could be defined as any action that is preceded by and caused by such a neural state. But if the RP does not reflect such a state, then either we must look for another putative correlate or else consider that "voluntary action" may not be a well-defined category in terms of neural phenomena. Rather, it may be a perceptual attribution: an action is voluntary if and only if it is perceived by the agent as being voluntary. This perception presumably must have some neural basis (unless one is a dualist). However, it seems important to distinguish the scientific project of searching for neural mechanisms of SIAs, from the project of searching for neural mechanisms of actions perceived as voluntary. This distinction is 
highlighted by a number of clinical conditions, which show that apparently voluntary actions may be perceived as involuntary (see below).

\section{Neurological alterations of conscious intention}

Consciousness of volition is fundamental to the experience of healthy adult humans. It provides the foundation for an individual to attribute agency to the self, and for society to attribute responsibility to an individual. What makes a movement feel voluntary, and what might make it feel involuntary? Studies of several neurological and psychiatric conditions have helped to answer this question because the behavior of these patients is consistent with an altered experience of volition.

The conditions of schizophrenia, alien hand syndrome (AHS), and psychogenic movement disorders (Scepkowski and CroninGolomb, 2003; Jeannerod, 2009; Hallett et al., 2012) all provide crucial evidence regarding the neurobiological basis of volition. This evidence is of clinical and even legal significance, as well as scientific significance. In this section, we describe the crossfertilization between basic and clinical neuroscience in understanding volition.

Psychogenic movement disorders, also referred to as "functional" or "nonorganic" movement disorders, fall into the category of (currently) medically unexplained symptoms. A patient with psychogenic movement disorder presents unwanted muscle movement, such as tremor or dystonic posturing, which cannot be voluntarily controlled. Despite being experienced by the patient as involuntary, the abnormal movements share certain characteristics with volitional movement. For example, psychogenic movements are susceptible to distraction and entrainment, such that asking the patient to perform a demanding voluntary task will temporarily stop the unwanted psychogenic movements, and tapping with their unaffected hand will entrain their psychogenic movement to the same frequency (Kranick and Hallett, 2013). By contrast, abnormal movements of patients with organic movement disorders (i.e., those with known neurological causes) are not affected by such distractions. Brain imaging also suggests that psychogenic movements share neural mechanisms with voluntary movements, as shown by a "motor RP" preceding the movement, which can be measured using EEG (Terada et al., 1995; Kranick and Hallett, 2013). So, why do these patients deny having any control over movements that, from a neurophysiological perspective, appear volitional?

One recent study with healthy volunteers sheds light on possible pathological mechanisms underlying distorted volition in psychogenic movement disorders. Douglas et al. (2015) asked healthy volunteers to perform self-generated movements during anodal or sham high-definition transcranial direct current stimulation (HD-tDCS). The volunteers reported the timing of the movement ("M-time") or intention ("W-time") by repositioning the hand of a rotating clock (Libet et al., 1983) to the position when they actually moved (M), or when they first became aware of the intention to move $(\mathrm{W})$. In previous studies, volunteers reported M-time and W-time at $\sim 70 \mathrm{~ms}$ and $\sim 200 \mathrm{~ms}$ before movement onset, respectively (Libet et al., 1983; Haggard, 2008). Interestingly, patients with psychogenic tremors, the most prevalent $(30 \%-40 \%)$ form of psychogenic movement disorder, report $\mathrm{W}$-times that are much closer to movement onset, as if they lacked awareness of their impending voluntary movement until just before actually moving (Edwards et al., 2011).

Douglas et al. (2015) observed that a single 20 min session of anodal HD-tDCS, designed to enhance neural excitability in either the left angular gyrus (AG) or the left primary motor cortex
(M1), caused the reported time of movement intention (W-time) to be $60-70 \mathrm{~ms}$ earlier than under sham stimulation. There was no effect on M-time or on the movement itself. Using EEG recording, they identified the brain processes underlying this behavioral effect: slow brain waves recorded $2-3 \mathrm{~s}$ before, as well as hundreds of milliseconds after, movement onset, independently correlated with the tDCS-induced modulation of W-time. These together accounted for $81 \%$ of the variance in the $\mathrm{W}$ judgments. The results suggest that conscious intention depends on brain processes extended over several seconds. The stimulation further showed that neural circuits underlying conscious intention can be manipulated independently from movement itself.

Previous lesion and cortical stimulation studies implicated the AG in generating conscious movement intention (Sirigu et al., 2004; Desmurget et al., 2009). Importantly, patients with psychogenic tremors exhibit hypoactivity of the AG during their psychogenic tremors, compared with their voluntary movements (Voon et al., 2010). This raises the intriguing possibility that during psychogenic tremors, abnormally low activity in AG reflects weakened movement intention, and, in turn, the patient's lack of sense of volition.

AHS is a neurological condition in which patients experience their limb movements as unaccompanied by any sense of agency. Three variants of AHS have been described: frontal, posterior, and callosal (Hassan and Josephs, 2016). In Figure 1, we outline a preliminary diagram of the neural circuitry underlying voluntary movement, inspired by the computational model put forward by Douglas et al. (2015), and indicate the location of cortical damage in the three variants of AHS.

The frontal variant of AHS typically arises from damage to the dominant (left) hemisphere in the SMA, anterior cingulate gyrus, or medial prefrontal cortex. The affected limb tends to reach and grasp for objects that are in the visual field (i.e., the unwanted movements are in response to external cues). These patients are aware that the alien limb belongs to them but are unable to suppress its unwanted movements, which are moreover experienced as involuntary (Hassan and Josephs, 2016).

The posterior variant of AHS typically involves damage to the nondominant (right) parietal lobe and affects the left hand. In contrast with the other variants, these patients have a strong sense of estrangement or disownership regarding the affected limb, and execute simpler movements, such as arm levitation. Brain regions active during alien and voluntary movements of the affected limb were examined using fMRI in a patient with a right parietal lobe lesion (Assal et al., 2007). Alien movements of the left limb were associated with isolated activity in the right M1, whereas voluntary movements were associated with a distributed network involving the M1, premotor cortex, and the inferior parietal lobule (IPL). The activity of the right M1 was not significantly different between alien and voluntary movements. This suggests that the alien movement was related to M1 activity when released from intentional control by the IPL. The patient was also often unaware of his alien movements. This could have been due to the impaired ability of the IPL to process sensory feedback (Farrer et al., 2003; Nahab et al., 2011) or secondary to spatial neglect (He et al., 2007).

Last, the callosal variant of AHS exclusively affects the nondominant (left hand) in right-handed patients and is mostly caused by isolated corpus callosum injury (Hassan and Josephs, 2016). This variant is characterized by intermanual conflicts, with minimal limb weakness and absence of frontal features. Overall, AHS demonstrates an interesting hemispheric asymmetry in which frontal and posterior variants tend to involve dominant 
$\mathrm{L}$

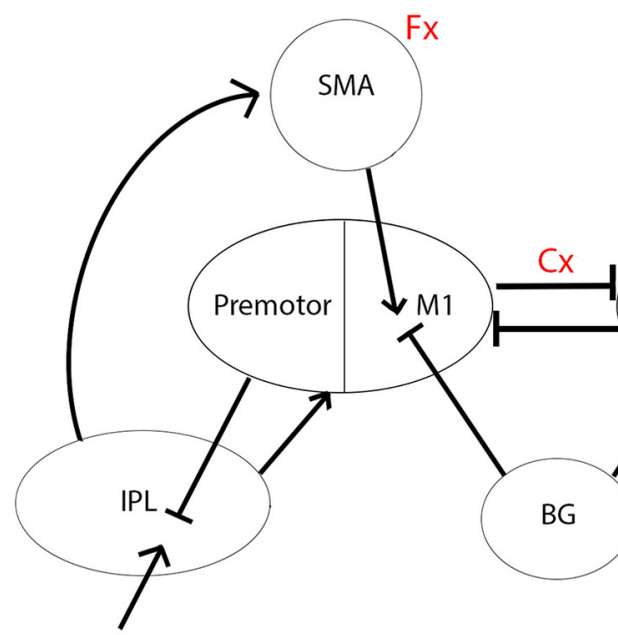

Sensory feedback
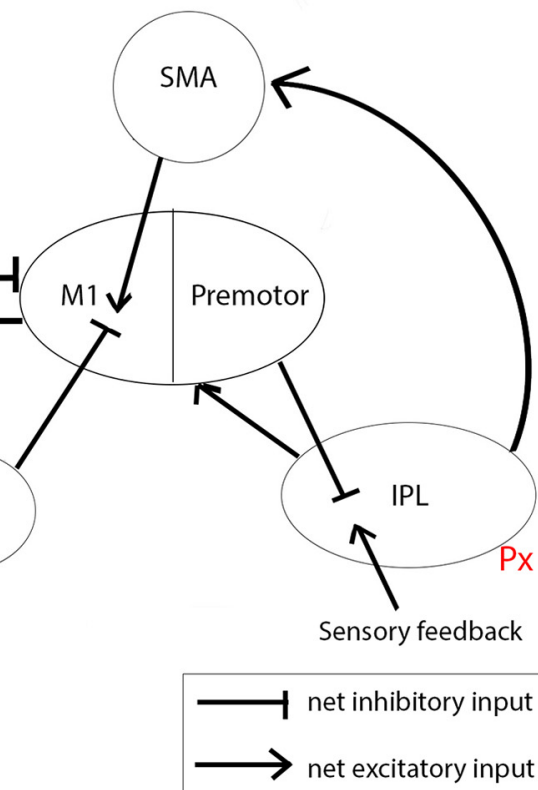

Figure 1. A proposed diagram for the neural circuit underlying normal and abnormal voluntary movement, following the computational model put forward by Douglas et al. (2015). In brief, IPL sends a sustained excitatory input to motor, premotor, and SMA areas starting from seconds before movement onset. SMA sends an excitatory input to M1 more proximal to movement onset, releasing the $\mathrm{M} 1$ from inhibition by basal ganglia (BG). Accompanying movement execution, AG receives a net-inhibitory input from M1 corresponding to the efference copy, and compares state estimates computed from efference copy with sensory feedback for online error correction (Wolpert et al., 1995; Desmurget et al., 1999). Red fonts indicate the location of cortical damage in three variants of AHS: Fx, Frontal variant; $\mathrm{C}$, callosal variant; Px, posterior variant.

and nondominant hemispheres, respectively, and disconnection of the two hemispheres seems to affect exclusively the nondominant hand. Although healthy volunteers are entirely able to generate voluntary movements of either the right or the left hand (indeed, this ability has been used as a marker of volition) (BrasilNeto et al., 1992), these observations suggest that the capacity for volition may be distributed unequally across the cerebral hemispheres.

\section{Goals and control: what is voluntary action for?}

Investigations of volition in human cognitive neuroscience often begin by distinguishing internally generated action from externally triggered action (Passingham, 1987). However, the characteristic feature of human voluntary action, in contrast to other animals, may be in how the capacity for internal generation is used. In this section, we link volition to the neurocognitive concept of goal-directed action. People and animals often make actions for a reason (Anscombe, 1957). The concept of goal-directed action in animal cognition (Dickinson and Balleine, 2002) overlaps with the concept of voluntary action in the crucial respects of absence of external trigger stimuli, and presence of reasons. Goal-directed action requires both an incentive or motivation, and an acquired instrumental knowledge of how specific motor actions can achieve the incentivised outcome (Balleine and Dickinson, 1998). Through biological evolution, and perhaps through cultural evolution also, the neurocognitive mechanisms of human voluntary action have developed markedly beyond those of other animals. The striking sophistication of human voluntary action is clear in both the incentive/motivational, and the instrumental aspects of action control (Fig. 2).
$\mathrm{R}$

First, on the motivational side, the goals or outcomes of voluntary action are more varied, and more flexible in humans than in animals. In animal studies, goaldirected actions classically involve search for primary reinforcers (food, water, etc.). In humans, voluntary actions may be directed at more abstract goals, or "higher" needs (Maslow, 1954). Indeed, humanspecific cultural actions, such as artistic expression, are often taken as paradigm cases of human voluntary action. Although such actions may account for only a tiny proportion of human goal-directed actions, they are of particular interest to cognitive neuroscience.

Second, on the instrumental side, the human brain supports much more complex relations between means and ends than is the case for other animals. Hebb (1949) emphasized the importance of what he called "motor equivalence" or "motor equifinality" in control of action. There are typically several different means to achieve any given action goal. For example, in a striking instance of motor equifinality, stimulating motor cortical areas in nonhuman primates caused arm movements to the same final posture, independent of starting posture (Graziano et al., 2002). Nevertheless, the brain must generate just one single, specific action, using an inverse model for action selection (Ghahramani and Wolpert, 1997; Rowe and Passingham, 2001). In humans, this flexibility of means-ends linkage, and the computational complexity of the resulting action selection problem, seem unlimited. The human capacity for future thinking and simulation enables distant goals (e.g., a successful career), which can be achieved in many ways. The hierarchical organization of many human voluntary actions may be essential to this flexibility (Koechlin et al., 2003).

Action-generation and decision-making are often studied in stimulus-driven situations, which typically underestimate the degree of internal generation of information involved in human volition. Here we take one illustrative paradigm from modelbased reinforcement learning. Participants first chose between two stimuli, which are probabilistically mapped to two further pairs of stimuli, which always differ in expected action value. Model-based decision-making implies selecting the first action taking into account the expected value of reward in responding to second-stage stimuli. The probability structure of the transition between the first and second stages allows mere habitual repetition of previously rewarded actions to be distinguished from deliberate planning to achieve the optimal outcome.

In these studies, the reward is typically money, the number of steps between action and goal is typically small (i.e., 2), and the number of possible choices is also small (i.e., 2). However, the architecture resembles more complex policies, involving a wider range of choices, that are typically considered voluntary, and for which we hold people responsible (Shadlen and Roskies, 2012). On this view, the distinguishing cognitive feature of voluntary action, as of model-based decision-making, might simply be "think before you act." Neuroimaging studies point to the frontal 


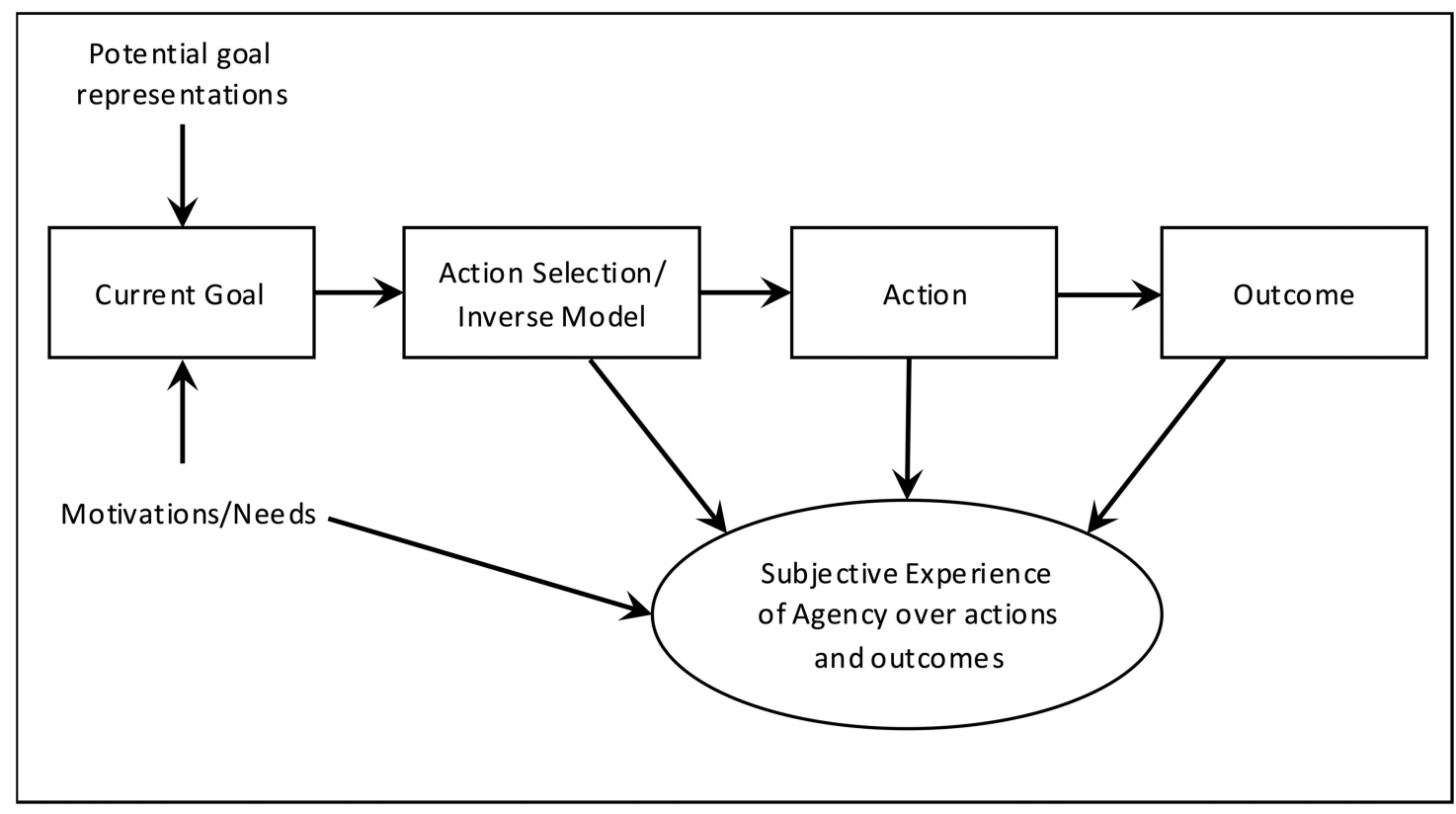

Figure 2. Volitional control involves representing, and then exploiting, regularities in the relation between actions and outcomes. The subjective experience is also influenced by both motivational (goals) and instrumental (action selection) processes.

and prefrontal cortices as critical nodes for model-based, as opposed to model-free, decision-making (Doll et al., 2015).

Recent cognitive neuroscience studies confirm the dual foundations of volition in motivational and instrumental processes. Interestingly, these studies further show that the characteristic subjective experience of agency that accompanies voluntary action (i.e., the feeling that one controls at will one's own actions, and, through them, events in the outside world) depends on both motivational factors (caring about outcomes) and instrumental factors (ability to control outcomes). Borhani et al. (2017) used the intentional binding effect to investigate the motivational and instrumental aspects of voluntary control. In intentional binding, a voluntary action and an outcome occurring shortly afterward are perceived as shifted toward each other in time. In contrast, a physically similar involuntary movement evoked by transcranial magnetic stimulation, and followed by a similar outcome, show no such binding (Haggard et al., 2002). Borhani et al. (2017) asked participants to choose between one of two actions that were probabilistically mapped onto lower or higher levels of laserevoked radiant heat pain. The participants were, unsurprisingly, motivated to reduce pain. Further, they showed stronger intentional binding, implying a stronger subjective sense of agency, when they could freely choose between actions and pain levels, than when their choice was instructed. That is, volitional decision regarding which action to make, to achieve a desired goal of reducing pain, produced stronger subjective experience of agency and control. This study highlights the importance for the experience of volition of internally generating information about which specific action to make, based on motivational goal.

A second study, focused specifically on this action selection process, and again linked the information-generation process to the subjective sense of agency. Khalighinejad et al. (2016) studied the shift in the perceived time of action toward outcome (one part of the intentional binding effect), across seven separate tDCS experiments, and used meta-analysis to investigate the pattern of results. They found that anodal tDCS over left DLPFC systemat- ically increased this intentional binding effect in studies involving an element of action selection.

Thus, a distinctive feature of human voluntary action involves thinking ahead about which of several actions to make to achieve a desired goal, in the absence, or relative absence, of external guidance. In this sense, volition and planning seem inseparable (Stuss and Alexander, 2007). These thought processes are associated with a distinctive subjective experience, which has been described as a metacognitive sense of agency (Metcalfe and Greene, 2007). The neuroscientific evidence suggests that the frontal and prefrontal cortex play a crucial role in the goal-directed aspects of human voluntary action. Scientific discussions of the neural and experiential aspects of voluntary action cannot ignore goaldirectedness. While parietal circuits seem to underpin the sense that the current action is mine, the frontal and prefrontal lobes seem crucial for the sense of what the action is for.

In conclusion, volition has historically been the domain of philosophical, rather than scientific, inquiry. However, an important tradition in systems neuroscience, inspired by the clinical neurology of the motor system, has long recognized a distinct class of actions that differ from reflexes in being relatively stimulusindependent, or "internally generated." Internally generated action remains a compelling construct for modern neuroscience and provides a useful operational definition for neuroscientific studies of human volition. Current research suggests that volitional control circuits are widely distributed in the brain, across the frontal and parietal lobes. However, the neurocomputational basis of volition, which may comprise both stochastic and deterministic components, remains an active research topic. Cognitive models point to a crucial role of both motivational and instrumental mechanisms in volition. Previous research traditions looking for a single neural center for human volition may have underestimated the distributed, multicomponent nature of volition. Indeed, "classical" paradigms for studying self-initiated action seem to lack ecological validity. New paradigms based on ecological selfgenerated actions, such as patch-leaving, may better capture everyday human volition, and have already identified potential 
neural precursors (Khalighinejad et al., 2017). Experimental methodology remains a key challenge for this intriguing and important neuroscientific research field.

\section{References}

Anscombe GEM (1957) Intention. Cambridge, MA: Harvard UP.

Assal F, Schwartz S, Vuilleumier P (2007) Moving with or without will: functional neural correlates of alien hand syndrome. Ann Neurol 62:301306. CrossRef Medline

Balleine BW, Dickinson A (1998) Goal-directed instrumental action: contingency and incentive learning and their cortical substrates. Neuropharmacology 37:407-419. CrossRef Medline

Borhani K, Beck B, Haggard P (2017) Choosing, doing, and controlling: implicit sense of agency over somatosensory events. Psychol Sci 28:882893. CrossRef Medline

Brasil-Neto JP, Pascual-Leone A, Valls-Solé J, Cohen LG, Hallett M (1992) Focal transcranial magnetic stimulation and response bias in a forcedchoice task. J Neurol Neurosurg Psychiatry 55:964-966. CrossRef Medline

Caspar EA, Christensen JF, Cleeremans A, Haggard P (2016) Coercion changes the sense of agency in the human brain. Curr Biol 26:585-592. CrossRef Medline

Dennett DC, Kinsbourne M (1992) Time and the observer: the where and when of consciousness in the brain. Behav Brain Sci 15:183-247. CrossRef

Desmurget M, Epstein CM, Turner RS, Prablanc C, Alexander GE, Grafton ST (1999) Role of the posterior parietal cortex in updating reaching movements to a visual target. Nat Neurosci 2:563-567. CrossRef Medline

Desmurget M, Reilly KT, Richard N, Szathmari A, Mottolese C, Sirigu A (2009) Movement intention after parietal cortex stimulation in humans. Science 324:811-813. CrossRef Medline

Dickinson A, Balleine B (2002) The role of learning in the operation of motivational systems. In: Stevens' handbook of experimental psychology. Hoboken, NJ: Wiley.

Doll BB, Duncan KD, Simon DA, Shohamy D, Daw ND (2015) Modelbased choices involve prospective neural activity. Nat Neurosci 18:767772. CrossRef Medline

Douglas ZH, Maniscalco B, Hallett M, Wassermann EM, He BJ (2015) Modulating conscious movement intention by noninvasive brain stimulation and the underlying neural mechanisms. J Neurosci 35:7239-7255. CrossRef Medline

Edwards MJ, Moretto G, Schwingenschuh P, Katschnig P, Bhatia KP, Haggard P (2011) Abnormal sense of intention preceding voluntary movement in patients with psychogenic tremor. Neuropsychologia 49: 2791-2793. CrossRef Medline

Farrer C, Franck N, Georgieff N, Frith CD, Decety J, Jeannerod M (2003) Modulating the experience of agency: a positron emission tomography study. Neuroimage 18:324-333. CrossRef Medline

Fried I, Katz A, McCarthy G, Sass KJ, Williamson P, Spencer SS, Spencer DD (1991) Functional organization of human supplementary motor cortex studied by electrical stimulation. J Neurosci 11:3656-3666. Medline

Fried I, Mukamel R, Kreiman G (2011) Internally generated preactivation of single neurons in human medial frontal cortex predicts volition. Neuron 69:548-562. CrossRef Medline

Ghahramani Z, Wolpert DM (1997) Modular decomposition in visuomotor learning. Nature 386:392-395. CrossRef Medline

Gold JI, Shadlen MN (2003) The influence of behavioral context on the representation of a perceptual decision in developing oculomotor commands. J Neurosci 23:632-651. Medline

Graziano MS, Kastner S (2011) Human consciousness and its relationship to social neuroscience: a novel hypothesis. Cogn Neurosci 2:98-113. CrossRef Medline

Graziano MS, Taylor CS, Moore T (2002) Complex movements evoked by microstimulation of precentral cortex. Neuron 34:841-851. CrossRef Medline

Haggard P (2008) Human volition: towards a neuroscience of will. Nat Rev Neurosci 9:934-946. CrossRef Medline

Haggard P (2011) Decision time for free will. Neuron 69:404-406. CrossRef Medline

Haggard P, Clark S, Kalogeras J (2002) Voluntary action and conscious awareness. Nat Neurosci 5:382-385. CrossRef Medline

Hallett M, Lang AE, Jankovic J, Fahn S, Halligan PW, Voon V, Cloninger CR (2012) Psychogenic movement disorders and other conversion disorders. Cambridge, UK: Cambridge UP.
Hassan A, Josephs KA (2016) Alien hand syndrome. Curr Neurol Neurosci Rep 16:73. CrossRef Medline

He BJ, Snyder AZ, Vincent JL, Epstein A, Shulman GL, Corbetta M (2007) Breakdown of functional connectivity in frontoparietal networks underlies behavioral deficits in spatial neglect. Neuron 53:905-918. CrossRef Medline

Hebb D (1949) The organization of behavior: a neuropsychological theory. New York: Wiley.

Jeannerod M (2009) The sense of agency and its disturbances in schizophrenia: a reappraisal. Exp Brain Res 192:527-532. CrossRef Medline

Khalighinejad N, Di Costa S, Haggard P (2016) Endogenous action selection processes in dorsolateral prefrontal cortex contribute to sense of agency: a meta-analysis of tDCS studies of "intentional binding." Brain Stimul 9:372-379. CrossRef

Khalighinejad N, Schurger A, Desantis A, Zmigrod L, Haggard P (2017) Precursor processes of human self-initiated action. Neuroimage. Advance online publication. Retrieved Sept. 28, 2017. doi: 10.1016/j.neuroimage. 2017.09.057. CrossRef Medline

Koechlin E, Ody C, Kouneiher F (2003 Nov 14) (2003) The architecture of cognitive control in the human prefrontal cortex. Science 302:1181-1185. CrossRef Medline

Kornhuber HH, Deecke L (2016) Brain potential changes in voluntary and passive movements in humans: readiness potential and reafferent potentials. Pflügers Archiv Eur J Physiol 468:1115-1124. CrossRef

Kranick SM, Hallett M (2013) Neurology of volition. Exp Brain Res 229: 313-327. CrossRef Medline

Libet B, Gleason CA, Wright EW, Pearl DK (1983) Time of conscious intention to act in relation to onset of cerebral activity (readiness-potential): the unconscious initiation of a freely voluntary act. Brain 106:623-642. CrossRef Medline

Maslow A (1954) Motivation and personality, Ed 1. New York: Harper and Brothers.

Metcalfe J, Greene MJ (2007) Metacognition of agency. J Exp Psychol Gen 136:184-199. CrossRef Medline

Nahab FB, Kundu P, Gallea C, Kakareka J, Pursley R, Pohida T, Miletta N, Friedman J, Hallett M (2011) The neural processes underlying selfagency. Cereb Cortex 21:48-55. CrossRef Medline

Passingham RE (1987) Two cortical systems for directing movement. Ciba Found Symp 132:151-164. Medline

Passingham RE, Bengtsson SL, Lau HC (2010) Medial frontal cortex: from self-generated action to reflection on one's own performance. Trends Cogn Sci 14:16-21. CrossRef Medline

Rowe JB, Passingham RE (2001) Working memory for location and time: activity in prefrontal area 46 relates to selection rather than maintenance in memory. Neuroimage 14:77-86. CrossRef Medline

Scepkowski LA, Cronin-Golomb A (2003) The alien hand: cases, categorizations, and anatomical correlates. Behav Cogn Neurosci Rev 2:261-277. CrossRef Medline

Schurger A, Sitt JD, Dehaene S (2012) An accumulator model for spontaneous neural activity prior to self-initiated movement. Proc Natl Acad Sci U S A 109:E2904-E2913. CrossRef Medline

Shadlen MN, Roskies AL (2012) The neurobiology of decision-making and responsibility: reconciling mechanism and mindedness. Front Neurosci 6:56. CrossRef Medline

Sherrington C (1906) The integrative action of the nervous system. New York: Oxford University Press.

Sirigu A, Daprati E, Ciancia S, Giraux P, Nighoghossian N, Posada A, Haggard $P$ (2004) Altered awareness of voluntary action after damage to the parietal cortex. Nat Neurosci 7:80-84. CrossRef Medline

Stuss DT, Alexander MP (2007) Is there a dysexecutive syndrome? Philos Trans R Soc Lond B Biol Sci 362:901-915. CrossRef Medline

Terada K, Ikeda A, Van Ness PC, Nagamine T, Kaji R, Kimura J, Shibasaki H (1995) Presence of Bereitschaftspotential preceding psychogenic myoclonus: clinical application of jerk-locked back averaging. J Neurol Neurosurg Psychiatry 58:745-747. CrossRef Medline

Voon V, Gallea C, Hattori N, Bruno M, Ekanayake V, Hallett M (2010) The involuntary nature of conversion disorder. Neurology 74:223-228. CrossRef Medline

Wittgenstein L (1967) Philosophical investigations. Oxford: Basil Blackwell. Wolpert DM, Ghahramani Z, Jordan MI (1995) An internal model for sensorimotor integration. Science 269:1880-1882. CrossRef Medline 